\title{
Inclusion Complex of a New Orally Active Cephalosporin ME1207 with $\beta$-Cyclodextrin
}

\author{
Mitsuru Tashiro, Emiko Magome, Shigeko Miki, and Kenji SaKagami*
}

Pharmaceutical Research Center, Meiji Seika Kaisha, Ltd., Morooka-cho, Kohoku-ku, Yokohama 222, Japan. Received December 4, 1991

The structure of a $1: 1$ inclusion complex of $\beta$-cyclodextrin $(\beta-C D)$ and a new orally active cephalosporin, pivaloyloxymethyl 7-[(Z)-2-(2-aminothiazol-4-yl)-2-(methoxyimino)acetamido]-3( $Z$ )-(4-methylthiazol-5-yl)vinyl-3cephem-4-carboxylate (ME1207), was estimated by nuclear magnetic resonance (NMR) analysis. The experimental results indicated that the tert-butyl moiety of ME1207 was selectively inserted into the $\beta$-CD cavity.

Keywords cephalosporin; oral cephalosporin; inclusion complex; NMR analysis; $\beta$-cyclodextrin; dissociation constant

In a previous paper, ${ }^{1,2)}$ we reported that pivaloyloxymethyl 7-[(Z)-2-(2-aminothiazol-4-yl)-2-(methoxyimino)acetamido]-3(Z)-(4-methylthiazol-5-yl)vinyl-3-cephem-4carboxylate (ME1207) was a new orally active cephalosporin and that the free acid ME1206, an active form of ME1207, showed potent and broad antibacterial activity against both gram-positive and gram-nagative bacteria. In

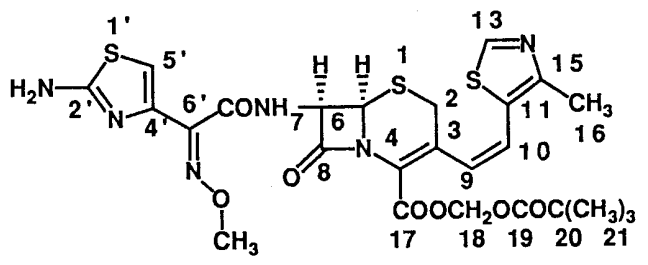

ME1207

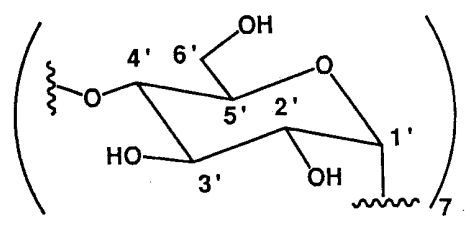

$\beta$-cyclodextrin $(\beta-\mathrm{CD})$

Fig. 1. Structure and Numbering of ME1207 and $\beta-\mathrm{CD}$ the course of studying the clinical evaluation of ME1207, it was found that the combination of ME1207 with $\beta$-cyclodextrin $(\beta$-CD) improves the urinary recovery of ME1207 after oral administration in dogs. ${ }^{3)}$ This result may come from the increasing solubility of ME1207 in water, presumably due to inclusion complex formation. In this paper, we report a structural evaluation of the complex of ME1207 and $\beta$-CD. ${ }^{4)}$

\section{Results and Discussion}

Secondary ion mass spectrometry (SIMS) of the $1: 1$ complex of the $\beta$-CD-ME1207 using dithiothreitol-dithioerythriol $(5: 1)$ as a matrix revealed a distinct peak at $\mathrm{m} / \mathrm{z}$ $1755(\mathrm{M}+\mathrm{H})^{+}$of the $\beta$-CD-ME1207 inclusion complex.

TABLE I. Chemical Shifts $\left(\delta_{\mathrm{H}} \mathrm{ppm}\right)$ of $\beta$-CD $(0.065 \mathrm{~N} \mathrm{DCl}$ Solution $)$ and $\beta$-CD-ME1207 $([\beta-\mathrm{CD}] /[\mathrm{ME} 1207]=4.8 \mathrm{~mm} / 4.8 \mathrm{~mm}, 0.065 \mathrm{~N}$ DCl Solution)

\begin{tabular}{lccc}
\hline \hline & $\beta$-CD & $\beta$-CD-ME1207 & $\Delta \delta^{a)}$ \\
\hline H-1' & 4.942 & 4.927 & -0.018 \\
H-2' & 3.523 & 3.521 & -0.002 \\
H-3' & 3.830 & 3.769 & -0.061 \\
H-4' & 3.452 & 3.446 & -0.006 \\
H-5' & 3.729 & 3.679 & -0.050 \\
\hline
\end{tabular}

a) Chemical shift displacement ( $\delta \beta-\mathrm{CD}-\mathrm{ME} 1207-\delta \beta-\mathrm{CD})$.

TABLE II. Induced Chemical Shift Changes $\left(\delta_{\mathrm{H}} \mathrm{ppm}\right)$ of ME1207 at Various Molar Ratios ([ME1207]/[ $\beta$-CD])

\begin{tabular}{|c|c|c|c|c|c|c|c|c|c|c|c|c|}
\hline$[\mathrm{ME1} 207]:[\beta-\mathrm{CD}]$ & $\mathrm{H}-21$ & $\mathrm{H}-16$ & $\mathrm{H}-2$ & $\mathrm{OCH}_{3}$ & $\mathrm{H}-7$ & H-18-1 & H-18-2 & $\mathrm{H}-6$ & $\mathrm{H}-9$ & $\mathrm{H}-10$ & H-5' & $\mathrm{H}-13$ \\
\hline $1.00: 0.00$ & 1.000 & 2.429 & 3.348 & 3.948 & 5.279 & 5.682 & 5.767 & 5.764 & 6.607 & 6.705 & 7.034 & 9.580 \\
\hline $1.00: 0.25$ & 1.027 & 2.435 & 3.354 & 3.950 & 5.282 & 5.687 & 5.757 & 5.773 & 6.607 & 6.706 & 7.035 & 9.584 \\
\hline$\Delta \delta(\mathrm{ppm})$ & 0.027 & 0.006 & 0.006 & 0.002 & 0.003 & 0.005 & -0.010 & 0.009 & 0.000 & 0.001 & 0.001 & 0.004 \\
\hline $1.00: 0.50$ & 1.047 & 2.437 & 3.355 & 3.947 & 5.280 & 5.687 & 5.745 & 5.777 & 6.608 & 6.703 & 7.034 & 9.595 \\
\hline$\Delta \delta(\mathrm{ppm})$ & 0.047 & 0.008 & 0.007 & -0.001 & 0.001 & 0.005 & -0.022 & 0.013 & 0.001 & -0.002 & 0.000 & 0.015 \\
\hline $1.00: 0.75$ & 1.057 & 2.439 & 3.357 & 3.947 & 5.280 & 5.688 & 5.739 & 5.779 & 6.609 & 6.702 & 7.031 & 9.596 \\
\hline$\Delta \delta(\mathrm{ppm})$ & 0.057 & 0.010 & 0.009 & -0.001 & 0.001 & 0.006 & -0.028 & 0.015 & 0.002 & -0.003 & -0.003 & 0.016 \\
\hline $1.00: 1.00$ & 1.067 & 2.440 & 3.359 & 3.947 & 5.281 & 5.688 & 5.734 & 5.782 & 6.609 & 6.702 & 7.033 & 9.600 \\
\hline$\Delta \delta(\mathrm{ppm})$ & 0.067 & 0.011 & 0.011 & -0.001 & 0.002 & 0.006 & -0.033 & 0.018 & 0.002 & -0.003 & -0.001 & 0.020 \\
\hline $1.00: 1.25$ & 1.070 & 2.440 & 3.359 & 3.946 & 5.280 & 5.688 & 5.732 & 5.783 & 6.608 & 6.702 & 7.032 & 9.600 \\
\hline$\Delta \delta(\mathrm{ppm})$ & 0.070 & 0.011 & 0.011 & -0.002 & 0.001 & 0.006 & -0.035 & 0.016 & 0.001 & -0.003 & -0.002 & 0.020 \\
\hline $1.00: 1.50$ & 1.074 & 2.442 & 3.359 & 3.947 & 5.281 & 5.689 & 5.731 & 5.783 & 6.609 & 6.702 & 7.033 & 9.601 \\
\hline$\Delta \delta(\mathrm{ppm})$ & 0.074 & 0.013 & 0.011 & -0.001 & 0.002 & 0.007 & -0.036 & 0.019 & 0.002 & -0.003 & -0.001 & 0.021 \\
\hline $1.00: 2.00$ & 1.078 & 2.442 & 3.361 & 3.946 & 5.280 & 5.689 & 5.728 & 5.785 & 6.608 & 6.701 & 7.032 & 9.600 \\
\hline$\Delta \delta(\mathrm{ppm})$ & 0.078 & 0.013 & 0.013 & -0.002 & 0.001 & 0.007 & -0.039 & 0.021 & 0.001 & -0.004 & -0.002 & 0.020 \\
\hline $1.00: 3.00$ & 1.084 & 2.444 & 3.362 & 3.947 & 5.282 & 5.690 & 5.727 & 5.787 & 6.609 & 6.702 & 7.034 & 9.603 \\
\hline$\Delta \delta(\mathrm{ppm})$ & 0.084 & 0.015 & 0.014 & -0.001 & $0: 003$ & 0.008 & -0.040 & 0.023 & 0.002 & -0.003 & 0.000 & 0.023 \\
\hline $1.00: 4.00$ & 1.088 & 2.444 & 3.363 & 3.947 & 5.282 & 5.691 & 5.726 & 5.788 & 6.609 & 6.702 & 7.033 & 9.602 \\
\hline$\Delta \delta(\mathrm{ppm})$ & 0.088 & 0.015 & 0.015 & -0.001 & 0.003 & 0.009 & -0.041 & 0.024 & 0.002 & -0.003 & -0.001 & 0.022 \\
\hline
\end{tabular}


This data indicates that a $\beta$-CD-ME1207 inclusion complex exists as a stable $1: 1$ inclusion complex in the gaseous phase. The structure of $\beta$-CD-ME1207 in $\mathrm{D}_{2} \mathrm{O}(0.065 \mathrm{~N}$ $\mathrm{DCl}$ solution, $\mathrm{pD}=$ about 1.2 ) was intensively studied by $400 \mathrm{MHz}$ nuclear magnetic resonance (NMR) spectroscopy.

The chemical shift changes of $\beta$-CD in the $\beta$-CD-ME1207 complex are listed in Table I. H-3' $(0.06 \mathrm{ppm})$ and $\mathrm{H}-5^{\prime}$ $(0.05 \mathrm{ppm})$ protons which are located inside the cavity of $\beta$-CD tours shift more than those of the other protons on the outer surface by the addition of a guest molecule. This implies that the guest molecule is inserted into the cavity of $\beta$-CD. ${ }^{5}$ )

TABLE III. Chemical Shifts $\left(\delta_{\mathrm{C}}\right.$ ppm $)$ of ME1207 $(0.0656 \mathrm{~N}$ DCl Solution) and $\beta$-CD-ME1207 ([ $\beta$-CD $] /[\mathrm{ME} 1207]=4.8 \mathrm{~mm} / 4.8 \mathrm{mM}, 0.065 \mathrm{~N}$ $\mathrm{DCl}$ Solution)

\begin{tabular}{|c|c|c|c|}
\hline & ME1207 & $\mathrm{ME} 1207-\beta-\mathrm{CD}$ & $\Delta \delta_{\mathrm{C}}(\mathrm{ppm})$ \\
\hline $\mathrm{C}-2$ & 29.13 & 29.17 & 0.04 \\
\hline $\mathrm{C}-4$ & 125.70 & 125.70 & 0.00 \\
\hline C-6 & 60.49 & 60.52 & 0.03 \\
\hline $\mathrm{C}-7$ & 58.42 & 58.45 & 0.03 \\
\hline C-8 & 165.81 & 165.42 & -0.39 \\
\hline C-9 & 132.01 & 132.16 & 0.15 \\
\hline C-10 & 120.63 & 120.67 & 0.04 \\
\hline C-11 & 132.99 & 132.55 & -0.44 \\
\hline C-13 & 156.57 & 156.67 & 0.10 \\
\hline C-15 & 145.63 & 145.57 & -0.06 \\
\hline C-16 & 12.94 & 13.01 & 0.07 \\
\hline C-17 & 163.09 & 163.13 & 0.04 \\
\hline C-18 & 81.90 & 81.65 & -0.25 \\
\hline C-19 & 180.58 & 179.58 & -1.00 \\
\hline $\mathrm{C}-20$ & 39.62 & 39.78 & 0.16 \\
\hline C-21 & 27.09 & 27.75 & 0.66 \\
\hline $\mathrm{C}-2^{\prime}$ & 143.35 & 143.37 & 0.02 \\
\hline$C-5^{\prime}$ & 112.16 & 112.19 & 0.03 \\
\hline $\mathrm{C}-6^{\prime}$ & 162.19 & 162.01 & -0.18 \\
\hline C- $7^{\prime}$ & 171.93 & 171.93 & 0.00 \\
\hline $\mathrm{OCH}_{3}$ & 64.96 & 64.96 & 0.00 \\
\hline
\end{tabular}
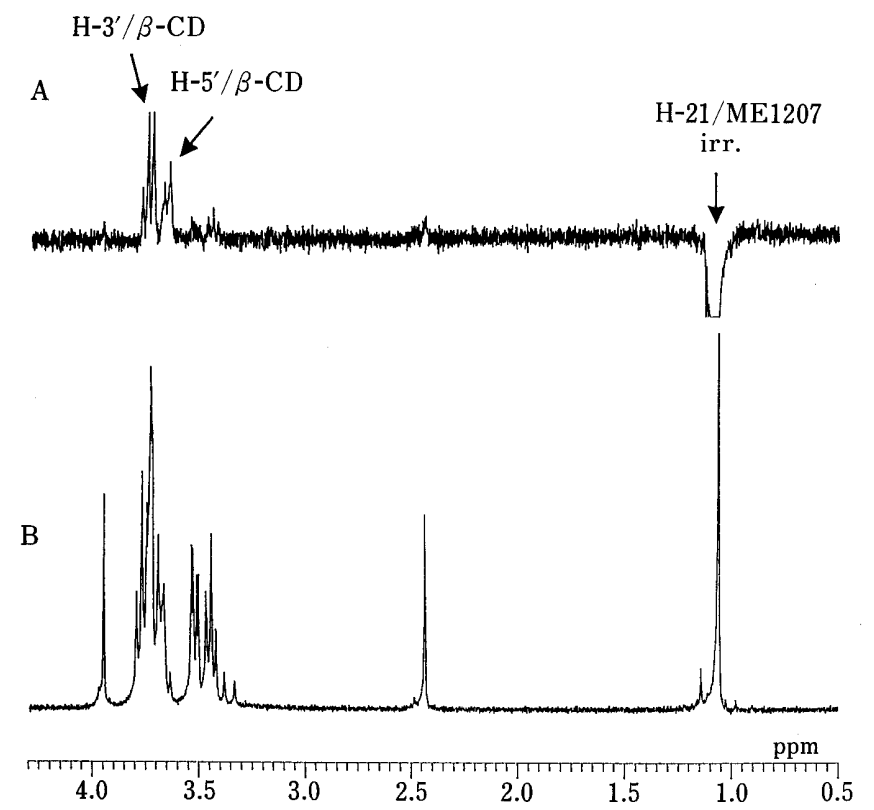

Fig. 2. ROE Difference Experiments with $\beta$-CD-ME1207 Complex

(A) Irradiation at $\mathrm{H}-21$ of $\mathrm{ME} 1207$; (B) $400 \mathrm{MHz}{ }^{1} \mathrm{H}-\mathrm{NMR}$ spectrum $([\beta-\mathrm{CD}] /[\mathrm{ME} 1207]=4.8 \mathrm{~mm} / 4.8 \mathrm{~mm}, 0.065 \mathrm{~N} \mathrm{DCl}$ solution $)$.
The chemical shift changes of ME1207 induced by added $\beta$-CD are illustrated in Table II in various molar ratios ([ME1207]/[ $\beta-\mathrm{CD}])$. Upon the addition of $\beta-\mathrm{CD}$, a downfield shift of the $\mathrm{H}-18$ proton and an upfield shift of the H-21 proton in ME1207 were also observed. These shifts were larger in comparison with those of other protons in ME1207, suggesting that the pivaloyl group of C-4 of ME1207 is selectively inserted into the $\beta$-CD cavity. The magnitude of the shifts of $\mathrm{H}-18$ and $\mathrm{H}-21$ increased as a function of an increasing ratio of $[\beta-\mathrm{CD}] /[\mathrm{ME} 1207]$ until the ratio became $1 / 1$, indicating that a rapid complexation process

$$
\mathrm{ME} 1207+\beta-\mathrm{CD} \rightleftharpoons[\mathrm{ME} 1207-\beta-\mathrm{CD}]
$$

was achieved. A modified Hildebrand-Benesi plot ${ }^{5)}$ of $\mathrm{H}-21$ shift data of ME1207 in the form of $[\beta-\mathrm{CD}] / \Delta \delta v s$. [ME1207] gave an excellent linear line. The dissociation constant of this inclusion complex, $K_{\mathrm{d}}$, was calculated to be $8.06 \times 10^{-4} \mathrm{M}$ by a least-squares fitting procedure from the plots.

These results supported the proposal that $\beta-\mathrm{CD}$ and ME1207 form a 1:1 inclusion complex. In addition to the larger shifts of $\mathrm{H}-18$ and $\mathrm{H}-21$ in ${ }^{1} \mathrm{H}-\mathrm{NMR}$ of the complex, ${ }^{13} \mathrm{C}-\mathrm{NMR}$ revealed noticeably larger shifts of C-19 (upfield shift, $1.00 \mathrm{ppm}$ ) and C-21 (downfield shift, $0.66 \mathrm{ppm}$ ) of ME1207 compared to other carbons (Table III).

These larger shifts also imply selective insertion of a pivaloyl group into the $\beta$-CD cavity. This is supported from the NMR measurement using the rotating-frame Overhauser enhancement $(\mathrm{ROE})^{6,7)}$ technique. Selective irradiation at $\mathrm{H}-21$ of ME1207 in the complex produced positive signals for both $\mathrm{H}-3^{\prime}$ and $\mathrm{H}-5^{\prime}$ of $\beta-\mathrm{CD}$ (Fig. 2), implying that the protons on tert-butyl $(\mathrm{H}-21)$ of the guest molecule underwent a comparable degree of intermolecular dipolar relaxation inside the $\beta$-CD cavity.

In conclusion, this data indicates that ME1207 forms a $1: 1$ inclusion complex with $\beta$-CD in which the tert-butyl entity of ME1207 is selectively inserted into the $\beta$-CD cavity.

\section{Experimental}

Materials $\beta$-Cyclodextrin $(\beta$-CD) was purchased from Tokyo Kasei Kogyo Co., Ltd. and used without further purification. ME1207 was synthesized by the method described in previous reports $\left.{ }^{1,2}\right)(95 \%$ purity). $\mathrm{D}_{2} \mathrm{O}$ (minimum isotopic purity 99.96 atom $\% \mathrm{D}$ ) and $20 \% \mathrm{DCl}$ solution in $\mathrm{D}_{2} \mathrm{O}(99$ atom $\% \mathrm{D})$ were used as solvents. These deuterated compounds were purchased from Aldrich Chemical Company, Inc.

Methods ${ }^{1} \mathrm{H}$ (resolution, $0.00065 \mathrm{ppm}$ ) and ${ }^{13} \mathrm{C}$ (resolution, $0.016 \mathrm{ppm}$ ) NMR spectra were taken on a JEOL GSX-400 spectrometer. Dioxane $\left(\sigma_{\mathrm{C}}=67.4 \mathrm{ppm}\right)$ and sodium 3-(trimethylsilyl)-1-propansulfonate $\left(\sigma_{\mathrm{H}}=\right.$ $0.00 \mathrm{ppm}$ ) were used as internal standards for ${ }^{13} \mathrm{C}$ and ${ }^{1} \mathrm{H}-\mathrm{NMR}$ in $\mathrm{D}_{2} \mathrm{O}$, respectively. Chemical shifts are recorded in $\sigma$ values (s, singlet; d, doublet; $\mathrm{t}$, triplet; $\mathrm{q}$, quartet; $\mathrm{m}$, multiplet; br, broad) and coupling constants in hertz $(\mathrm{Hz}) .{ }^{1} \mathrm{H}-{ }^{13} \mathrm{C}$ NMR shift correlation spectra (COSY) were obtained with JEOL standard software. Assignments of all ${ }^{1} \mathrm{H}$ and ${ }^{13} \mathrm{C}$ chemical shifts of ME1207 in $\mathrm{D}_{2} \mathrm{O}(\mathrm{pD}=$ about 1.2$)$ were unambiguously carried out by decoupling experiments including ${ }^{1} \mathrm{H}-{ }^{1} \mathrm{H}$ and ${ }^{1} \mathrm{H}^{-13} \mathrm{C}$ COSY measurements. SIMS was taken with a Hitachi M-80B mass spectrometer.

Preparation of ME1207 and $\boldsymbol{\beta}$-CD Inclusion Complex The inclusion complex of ME1207 and $\beta-\mathrm{CD}$ was prepared by the addition of equimolar ME1207 to $\beta-\mathrm{CD}$ in $0.065 \mathrm{~N}$ of a DC1 solution ( $\mathrm{pD}=$ about 1.2$)$. From ${ }^{1} \mathrm{H}-\mathrm{NMR}$ spectrum, ME1207 in this solution was stable for $1 \mathrm{~d}$ at room temperature. The $0.065 \mathrm{~N} \mathrm{DCl}$ solution was prepared from $20 \% \mathrm{DCl}$ solution in $\mathrm{D}_{2} \mathrm{O}(99 \%$ atom $\% \mathrm{D})$ and $\mathrm{D}_{2} \mathrm{O}$ (minimum isotopic purity 99.96 atom $\%$ D).

Determination of ME1207- $\beta$-CD Dissociation Constant by ${ }^{1} \mathrm{H}-\mathrm{NMR}$ 
The concentration of ME1207 was held constant at $4.8 \mathrm{mM}$, and $\beta$-CD concentration varied between $0.00-19.2 \mathrm{~mm}$. The change in chemical shift of the H-21 proton of ME1207 was measured as a function of changing $\beta$-CD concentration. The data was treated according to a modified Hildebrand-Benesi equation.

\section{References and Notes}

1) K. Sakagami, K. Atsumi, A. Tamura, T. Yoshida, K. Nishihata, and S. Fukatsu, J. Antibiot., 43, 1047 (1990).

2) K. Sakagami, K. Atsumi, Y. Yamamoto, A. Tamura, T. Yoshida K. Nishihata, and S. Fukatsu, Chem. Pharm. Bull., 39, 2466 (1991).
3) T. Kikkoji, T. Kobayashi, T. Sato, K. Watanabe, and K. Nishizawa, Eur. Patent Apple. EP 339465 (1989) [Chem. Abstr., 113, 65243 c (1990)].

4) After this work, similar study of $\alpha-C D$ and penicillin $V$ inclusion complexation was reported; H. Qi, V. Mark, L. Diaz, D. M. Grant, and C. Chang, J. Org. Chem., 56, 1537 (1991).

5) Y. Yamamoto and Y. Inoue, J. Carbohyd. Chem., 8, 29 (1989).

6) A. Bax and D. G. Davis, J. Magn. Reson., 63, 207 (1985).

7) H. Kessler, C. Griesinger, R. Kerssebaum, K. Wagner, and R. R. Ernst, J. Am. Chem. Soc., 109, 607 (1978). 